\title{
Urbanity, Neighbourhood Characteristics and Perceived Quality of Life (QoL): Analysis of Individual and Contextual Determinants for Perceived QoL in 3300 Postal Code Areas in Finland
}

\author{
Mikko Weckroth ${ }^{1,2}$ (D) Sanna Ala-Mantila ${ }^{2} \cdot$ Dimitris Ballas $^{3} \cdot$ Thanasis Ziogas $^{3}$. \\ Jonna Ikonen ${ }^{4}$
}

Accepted: 19 October 2021 / Published online: 2 February 2022

(c) The Author(s) 2022

\begin{abstract}
This analysis examines the geography of subjective wellbeing within a single country via a novel dataset consisting of more than 26,000 respondents embedded in 3100 postal code areas in Finland. We include a detailed indicator on the level of urbanity of the respondent's location derived from a $250 \times 250 \mathrm{~m}$ GIS grid, contextual measures of the postal code area's socioeconomic status as well as proximity to the nearest urban locality and capital city. This analytical framework model makes it possible to examine both individual and contextual determinants for perceived quality of life (QoL). In addition, we include individual-level measures on mental health (Mental Health Inventory MHI-5) and satisfaction with housing and neighbourhood characteristics. The results show that when controlling for socioeconomic factors living in an inner urban area or a neighbourhood (postal code area) with a high unemployment rate are associated with lower QoL and. Also, the share of population with a tertiary education in a postal code area has a positive effect for individual QoL. However, the effects of inner urban living and unemployment rate become insignificant when including mental health indicators and perceived loneliness. In sum, the results confirm and add more detail to earlier findings on lower QoL in urban context and connect living in inner urban area to mental health indicators. As such, the analysis provides further evidence for the positive QoL effects of more rural living while having an access to health and other services.
\end{abstract}

Keywords Quality of life · Urban-rural differences · Urban happiness penalty · Geography of happiness

Mikko Weckroth

mikko.weckroth@luke.fi

Extended author information available on the last page of the article 


\section{Introduction}

The last few decades have witnessed increasing interest throughout the social and behavioural sciences in measuring the levels of subjective wellbeing (henceforth, SWB) of individuals (e.g. Diener et al., 2018). In parallel, geographically referenced survey data containing such measures have become increasingly available. These developments have given rise to a branch of academic literature in social sciences that can be labelled the "geography of happiness" literature (Ballas, 2013; Ballas \& Tranmer, 2012; Berry \& Okulizc-Kozaryn, 2011; Berry \& Okulicz-Kozaryn, 2009; Brereton et al., 2008; Knight et al., 2009; Lenzi \& Perucca, 2016, 2020; Morrison, 2011; Morrison \& Weckroth, 2018; Okulicz-Kozaryn, 2017; Piper, 2014; Pittau et al., 2010; Requena, 2016; Sørensen, 2014, 2021).

Most "geography of happiness" studies have focused on the differences in perceived life satisfaction ${ }^{1}$ between large cities and more rural surroundings ( Berry \& Okulicz-Kozaryn, 2009; Morrison, 2011; Morrison \& Weckroth, 2018; Okulicz-Kozaryn, 2017; Sørensen, $2014,2021)$. This branch of literature has been theoretically invigorated by classic urban sociology studies discussing the socio-psychological consequences of living in a large metropolis (Durkheim, 1893; Simmel, 1903; Wirth, 1938). Hence, this literature emphasizes social segmentation leading to feelings of alienation, exclusion and loneliness associated with the manner in which social life is organized in large cities. However, Savage et al. (2003) note that urban-rural relations should be seen more as a continuum than a strict binary, wherein the use of one-dimensional measures of urbanity has led to inconsistent results regarding whether such an "urban happiness penalty" (Piper, 2014) actually exists. As such, it remains unclear if such an effect is related to subjective perceptions of urbanity, to the more objective socioeconomic status of an urban neighbourhood, or alternatively, to satisfaction with neighbourhood characteristics or accessibility to services. Additionally, some studies have examined the rural-urban differences in individual-level social capital (Requena, 2016; Sørensen, 2014, 2021) and rural-urban differences in access to nature and green spaces (Sørensen, 2021) when examining the existence and potential causes of the "urban happiness penalty". In technical terms, this existing literature has focused on measures of population density (Cramer et al., 2004), the binary between a capital city and the rest of the country (Smarts, 2012; Piper, 2014; Morrison \& Weckroth, 2018), or subjective evaluations by respondents on the urbanity of their living environment or the size of their city of residence (Requena, 2016; Sørensen, 2014).

Each of these measures captures different aspects of urbanity involving different spatial designs, and as a result, we have rather inconsistent information on just where the negative effect of urban/rural living is located. Also, the geographical literature on SWB listed

\footnotetext{
1 The literature reviewed here as studies on "geography of happiness" is subject to rather imprecise conceptual framing regarding the dependent variable being examined. Therefore, this paper aligns itself with the most common form of classification when measuring subjective well-being (e.g. OECD, 2013), which distinguishes between three theoretical accounts and related measures: (1) a life evaluations account (evaluative measures), (2) a hedonistic account (affect measures) and (3) a eudaimonic account (flourishing and functioning measures) (see also Kristjansson, 2010). This distinction is especially relevant for analyses on the geography of SWB, since recent studies (Burger et al., 2020) have shown that the urban-rural gradient can be identified only via evaluative measures. The concepts of SWB and happiness are referred to here as umbrella concepts covering the abovementioned three dimensions and measures. Quality of life (QoL), however, is referred to as a single item measure of SWB that is best positioned in the life evaluations account (see, e.g. Michalos, 2014).
} 
above have very seldomly utilized psychometric measures on mental health ${ }^{2}$ (for an exception see e.g. Okulicz-Kozaryn \& Valente, 2020), but instead the causes for urban-rural differences are sought from more cultural explanations and concepts (e.g. social capital and institutional and interpersonal trust). Thus, within the "geography of happiness" literature the proof for a negative effect on urbanity is still rather vague concerning which psychosocial attributes (e.g. mental health, anxiety, nervousness or loneliness) are associated with the potential negative effect of urban context.

Another more technical limitation of the existing "geography of happiness" literature is that the sample sizes of the datasets have been rather small for geographical analysis and the level of geographical resolution thus too crude to shed light on the within-city scale (e.g. neighbourhood level) of a place beyond the more generic urban-rural binary or gradient. The few analyses to focus on within-city scale have been conducted with non-representative sample surveys collected from a single-city region (e.g. Mouratidis, 2019) and usually not linked to the theoretical urban-rural discussion referred above. Therefore, the main interest of such within-city analyses has been on defining what neighbourhood characteristics are associated with SWB (Mouratidis, 2019, 2020) through survey items asking about an individual's level of satisfaction with different aspects of their living arrangement and area. Hence, they have not differentiated between the role of objectively defined and measured attributes related to one's neighbourhood (e.g. level of unemployment, lowincome households or other measure of socioeconomic status) and individual evaluations of housing and neighbourhood satisfaction.

Finally, it is possible to specify a third approach adopted in the "geography of happiness" literature that focuses on the role of accessibility, proximity and the general relationship between the spatial structure of a society and individual SWB (Hoogerbrugge et al., 2021; Lenzi \& Perucca, 2016, 2020). While this approach has theoretical foundations in spatial and urban economics, it has more recently been used to examine the role of accessibility to certain urban amenities with the analogy of "borrowed size". The key idea here is that each (housing) location is subject to multiple contexts, and hence, subject to the overlapping positive and/or negative externalities of urban agglomerations. In other words, even though living in a large city would be associated with a lower SWB per se, an individual could acquire an optimal "mix of contexts" by living in smaller communities or even rural surroundings but in proximity to a large city providing access to certain urban amenities.

In sum, despite the few recent contributions by Sørensen (2021) and Weckroth and Kemppainen (2021) scrutinizing different perceptions of urbanity, a majority of the existing "geography of happiness" literature has operated with single-dimensional measures of urban-rural divide. Thereby, the geographical focus has been, due to the nature of available datasets, either on rather broad urban-rural comparisons, or alternatively, on within-city scale with a focus on subjective evaluations of housing and neighbourhood satisfaction. As a result, they have not been able to differentiate between contextual effects at a neighbourhood scale and individual-level determinants of SWB.

This analysis combines these perspectives on "geography of happiness" into a single empirical scrutiny by utilizing a novel dataset that makes it possible to address the key limitations and open questions discussed above. To this end, we utilize a nationally representative

\footnotetext{
${ }^{2}$ However, within neuropsychology there exists a well-established line of research documenting the link between urban living and psychiatric disorders (Lederbogen et al., 2011; Peen et al., 2010).
} 
FinSote survey on health and wellbeing conducted by the Finnish Institute for Health and Welfare (THL) in 2018. The FinSote 2018 survey included more than 26,000 respondents embedded in 3100 postal code areas in Finland. Acknowledging the hierarchical nature of the data and applying the multilevel modelling (MLM) method enables us to address the contextual determinants of SWB for persons at the postal code level throughout Finland and not only in the largest cities. More specifically, we examine the role of the objective attributes of a postal code area (level of unemployment, low-income households, those with a tertiary education and population density) derived from the Paavo postal code area database provided by Statistics Finland as potential predictors of individual SWB. Additionally, we include various individual-level items on housing and neighbourhood satisfaction.

Additionally, this analysis makes a contribution to the existing literature by examining the relationship between the level of urbanity and individual SWB with multiple indicators of urbanity instead of relying only on technical and objective measure of population density or subjectively evaluated descriptions urbanity. We utilize a seven-point, urban-rural classification scale derived from a $250 \times 250 \mathrm{~m}$ grid of a respondent's home address constructed by the Finnish Environment Institute (SYKE), which provides a precise and objective measure of one's living environment. Additionally, and in line with Lenci and Perucca (2016, 2020), we also address the role of proximity to urban centres and related amenities in individual SWB by calculating the distance $(\mathrm{km})$ to the nearest urban locality and capital region from the centroid of each postal code area. Finally, through the empirical framework of this study we explicitly apply and emphasize the importance of an interdisciplinary approach by importing an established measure from psychiatric research to a more socio-culturally oriented "geography of happiness" literature. More specifically, we utilize a Mental Health Inventory (MHI-5) questionnaire, measuring psychological well-being with depressive symptoms and anxiety as well as an item on perceived loneliness.

In sum, we believe that with these advancements, this study presents the most detailed, multiscalar and interdisciplinary analysis to date on the geography of SWB within a single country. The previous literature suggests that the urban-rural SWB differences are localized in western context and in the most affluent countries (e.g. Berry \& Okulicz-Kozaryn, 2009; Easterlin et al., 2011, Weckroth \& Kemppainen, 2021). Hence, this analysis provides an intriguing insight to the within-country differences in a nation which has been named the happiest country in the world by the United Nations World Happiness Report (e.g. Helliwell et al., 2020). The article is structured as follows. First, we review the classic theses on the psychosocial effects of urban living. The subsequent section reviews the prior findings of "geography of happiness" studies conducted with the MLM method, making it possible to distinguish the contextual determinants of individual SWB, followed by a review of those studies that extended their focus from a broader urban-rural framing to include within-city scale. The rest of the article proceeds with a description of the data, measures and the method followed by a presentation of the results, conclusions and a discussion.

\section{Urbanity and Wellbeing}

The "geography of happiness" literature has been dominated by empirical analyses of the urban-rural differences in SWB and related classic urban sociology theories on the psychosocial effects of big-city living. The most influential advocates of these ideas are the classics scholars Luis Wirth and Georg Simmel, both of whom presented the 
social-psychological attributes of urban life in a rather negative light but approached the issue with slightly different points of emphasis.

First, the German essayist and philosopher Georg Simmel focused his take on The metropolis and Mental Life (Simmel, 1903), explicitly the psychology effects of living in a large urban metropolis. As such, Simmel's thesis was directed at the causal order between one's living environment and mental health. Simmel argued that human psychology is altered by city living through adaptation and adjustment as a response to the ways in which social and economic life are structured in a large metropolis. According to Simmel, a distinct feature of living in a modern urban metropolis is an intensification of nervous stimuli to which city dwellers must cope by adapting a so-called blasé attitude to his/her peers. Consequently, individuals in an urban environment become rational, calculative and socially reserved, leading to emotional isolation or dissociation. In sum, in Simmel's view the psychology of urban life is characterized by nervousness, anxiety and overall lower levels of mental health.

As such, Simmel also related the social consequences of urban life explicitly to a sense of loneliness. As he stated: "nowhere feels the individual as lonely and lost as in the metropolitan crowd" (Simmel, 1903, 7). What lay at the heart of Simmel's view on the urban realm is the paradox between the quality and quantity of social encounters; in Simmel's view, passing a thousand faces on a daily basis without recognition or interaction leads to dissociation, and in the end, to loneliness. More recently, the ideas of Simmel were refined by Donbavand (2020), who argued that the sense of urban loneliness has a structural (rather than personal or psychological) foundation related the relational system of interaction between individuals and collectivities.

While Wirth shared Simmel's negative perceptions of urban life, he emphasized more the socio-economic and political foundations of urban life and related them to the urban realm more explicitly in relation to the process of modernization. In Wirth's mind, urban life represents a localization of modern society, which is characterized by a highly developed division of labour leading to highly segmented professional—but inevitably also social-roles allocated to individuals and various socioeconomic groups. Hence, urbanization is entangled with the concept of heterogeneity and inevitably associated with the socioeconomic structures of modern-and urban-societies. In accordance with Simmel's ideas, Wirth also concluded that the volume, density and heterogeneity of urban residents inevitably entails being in physical proximity to socially distant co-residents, a setting that leads to social distance or inter-personal indifference. As Wirth $(1938,23)$ memorably puts it, "[t]he contacts of the city may indeed be face to face, but they are nevertheless impersonal, superficial, transitory, and segmental".

As described in the introduction, the literature on the urban happiness gradient has been persistent to find empirical evidence supporting the claims presented in classic urban sociology studies. However, the literature is subject to limitations regarding the measures used for addressing urbanity and also lacks established measures of mental health derived from more recent psychological studies. This analysis aims to shed more light on the debate about the relationship between urban living and mental health through by including a range of different measures of urbanity and psychometrically validated mental health (MHI-5) measures as well as a separate survey item on perceived loneliness. Moreover, we examine these indicators using the MLM method, which makes it possible to distinguish the contextual-level determinants of SWB from attributes pertaining to the individuals themselves. The following section reviews existing "geography of happiness" research following an MLM approach. 


\section{Multilevel Models and SWB Research}

Scholars have argued that the hierarchical structure of many datasets in the social sciences makes MLM approaches particularly suitable to studying urbanity, neighbourhood characteristics and perceived QoL. The MLM method allow researchers to explore such datasets and examine the effect of contextual factors at various scales, such as with individuals, households, neighbourhoods, regions and countries. There is a long and successful history of using such models in education studies, as students are typically nested within classes, schools and neighbourhoods (Aitkin \& Longford, 1986; Leckie, 2009). However, relatively few studies have applied such methods to analysing datasets with a hierarchical structure in SWB research. Existing "geography of happiness" studies make a strong argument for adopting an MLM approach given that individual SWB is contingent upon both individual and contextual factors at different scales. Thus, analysis of people's SWB makes it possible to include not only individual-level characteristics but contextual characteristics as well, since both micro-level and macro-level variables are now included in the specifications. Given the proliferation of relevant microdata, it is becoming increasingly possible to examine whether individuals nested in households in different neighbourhoods, regions and countries share some common attributes resulting from either similar or different levels of SWB. For example, two persons that share exactly the same individual characteristics may have different levels of SWB because one of them lives e.g. in a more densely populated area. Accordingly, when engaging with the "neighbourhood effects" debate in urban studies it is important to ask whether indicators on the socioeconomic status of the neighbourhood (e.g. share of unemployed or low-income households) have an impact on the SWB of the residents, which is independent of individual socioeconomic attributes, such as income or unemployment. This section reviews the papers that apply MLM techniques to capture the effect of contextual variables at various geographical levels on people's SWB levels.

The first paper to apply a multilevel data structure in SWB research used survey data from the US-based National Opinion Research Center's Continuous National Survey (CNS) for approximately 8000 individuals from the years 1973-1974 (Fernandez \& Kulik, 1981). The paper examined the effect of various contextual/neighbourhood characteristics on life satisfaction. Apart from the individual-level characteristics that proved statistically significant, the authors found that individuals living in neighbourhoods with a high cost of living are less satisfied with life compared to individuals in low-cost neighbourhoods. The mechanism they employed to arrive at such a result led to the conclusion that "persons living in high-cost neighborhoods have part of their material prosperity removed as a cost of residence" (Fernandez \& Kulik, 1981, p. 842). The authors also found that people in urban places score lower on life satisfaction compared to people in rural places.

Since then, a steadily increasing number of studies have focused on SWB (including self-rated health measures), with the most notable including a study by Subramanian et al. (2001), who addressed the nexus between income inequality, social capital and subjective health. They applied various multilevel regressions using random intercepts and random slopes at the individual and state level with data from the 1993-1994 Behavioral Risk Factor Surveillance System and 1986-1990 General Social Surveys. The survey asked 144,692 respondents nested within 39 US states the following question: "Would you say that in general your health is excellent, very good, good, fair or poor?" Their findings suggest that the effect of income inequality on subjective health depends on the different income groups examined. The likelihood of reporting poor health increases as one moves from high to low income groups. 
One example of MLM analysis conducted at a regional scale is often cited study by Pittau et al. (2010), who used Eurobarometer data with a sample of more than one million individuals from $15 \mathrm{EU}$ member countries. Using only economic variables, one of their findings is that in poor regions, personal income matters more than it does in rich regions. They also pointed out that the variation in life satisfaction between regions persists even after controlling for individual and regional characteristics. On the other hand, instead of looking at the income effects at various scales, as in previous studies, Aslam and Corrado (2012) examined the role of economic and non-economic factors in the life satisfaction of individuals. They asked what level of geographical aggregation matters the most for an individual's SWB. Utilizing data from the 2006 European Social Survey (ESS) and focusing on 20 countries, the authors examined the importance of individual, regional and country-level factors. Their empirical results suggest that both individual and regional characteristics are significant in relation to life satisfaction, however regional characteristics dominate over individual ones. On the other hand, Ballas and Tranmer (2012), focusing on the United Kingdom and using data from the 1991 British Household Panel Survey (BHPS), found that after controlling for contextual characteristics, the variability in happiness between places is insignificant and the only significant variation occurs between people. The authors arrived at these conclusions using the General Health Questionnaire (GHQ-12), measured on a scale from 0 to 36, as a proxy for subjective wellbeing as well as the general happiness question, which was a component of that questionnaire.

A number of studies also explore rural-urban differences in subjective wellbeing with MLM approach, with one of the first such attempts being the work done by Shucksmith et al. (2009), who used the European Quality of Life Survey (EQLS) for 28 countries. The authors applied a random slope multilevel model and found that location, whether urban or rural, is not a significant explanatory variable in relation to subjective wellbeing. However, a limitation of their analysis was that although they measured the original variable using a four-scale item, the authors merged some categories and used a binary independent variable.

Another important MLM analysis at neighbourhood level is a study done by Aminzadeh et al. (2013), who used data on approximately 9000 students retrieved from the Adolescent Health Research Group and applied a random intercept, multilevel model to assess the relationship between social capital at the neighbourhood level and the SWB of the students. Their findings highlight the importance of a neighbourhood's social environment for the wellbeing of adolescents: in neighbourhoods with higher levels of social cohesion, students report higher levels of subjective wellbeing.

In sum, the studies reviewed above are examples of the relatively limited efforts to date at adopting an MLM approach to analyse SWB. It should be noted that the geographical level of the analysis (at one level up from individuals and households) in most of the studies was the region, state or, in some cases, a coarse local district level. Therefore, the literature reviewed above is subject to two overlapping limitations: first, the level of geographical precision and detail concerning the spatial scale defined as the contextual level, and second, an adequate sample size based on the survey data. Zooming in on the spatial design of the analysis results in a diminishing number of respondents being allocated to each spatial unit. In other words, large enough datasets with an adequate number of observations in a small enough spatial design that would enable, in theoretical and empirical terms, an analysis of neighbourhood effects seldom exist.

Therefore, the research presented in this paper adds to this literature by using a large nationally representative, high-quality survey data from more than 26,000 respondents, disaggregated at the spatial level of 3100 postal code areas in Finland and combined with 
contextual data on the socioeconomic attributes of the various postal codes. As noted by Owen et al. (2016), defining a theoretically plausible spatial scale is of crucial importance for MLM analysis, and in this sense here the postal code is a good proxy for neighbourhood context, especially in large cities. Thus, this analysis contributes to the limited number of studies that have adopted a within-city scale approach to assess the relationship between neighbourhood characteristics and SWB. This branch of literature is reviewed in the following section.

\section{Neighbourhood Characteristics and SWB Research}

The focus of "geography of wellbeing" research has in recent years expanded to include the intra-urban scale, i.e. differences in wellbeing produced within cities, instead of just comparing different larger spatial entities, such as rural and urban contexts. This is relevant because of the increasing pace of urbanization, which necessitates that urban planning better understand how different types of urban externalities affect wellbeing and, ultimately, how we can plan cities that could even support the wellbeing of all citizens.

The earliest intra-urban research prioritized the effect of density on SWB, and the results offer no final conclusion on the effect of density: both negative and non-existing relationships have been reported (e.g. Arifwidodo, 2012; Cramer et al., 2004; Li \& Kanazawa, 2016). More recent attempts to address the issue of wellbeing at the intra-urban scale, such as studies by Ettema and Schekkerman (2016), Ala-Mantila et al. (2018), Mouratidis (2019) and Wang et al. (2019), have controlled for a wider set of neighbourhood-level variables, ranging from the built environment and socioeconomic structures to relative position in the neighbourhood.

For example, in a study using an earlier version of our FinSote data, Ala-Mantila et al. (2018) controlled for such objective neighbourhood variables as density, travel accessibility, inequality and relative position of persons compared to their 100 closest neighbours. They found that the results vary based on the dependent SWB variable being used. For example, the densest central pedestrian zones are related to higher QoL, whereas happiness was highest in car-oriented zones. They found that neighbourhood-level inequality and lower relative position are related to lower levels of happiness, but not to lower quality of life. However, they did not control for the socioeconomic structure of the neighbourhood per se at a more detailed level.

In addition to the objective variables describing a neighbourhood, studies by Ettema and Schekkerman (2016) and Ala-Mantila et al. (2018) both concluded that subjective spatial characteristics are more important for wellbeing than objective ones. Ettema and Schekkerman (2016) found that the perceived attractiveness of a neighbourhood affects life satisfaction and affective wellbeing the most, followed by its perceived social safety. They also controlled for subjective distance to amenities and various services and found only one significant relationship: life satisfaction and affective wellbeing increase with increasing distance to urban amenities. Ala-Mantila et al. (2018) found that the perceived safety of an area is most important for both subjective happiness and quality of life.

In his study of the Oslo metropolitan region, Mouratidis (2019) used three objective urban form attributes, compactness, distance to city centre and population density, in addition to the subjective attributes of neighbourhood safety, noise and cleanliness. However, he found no statistically significant relationships between the objective measures and SWB, while perceived safety also proved the most important subjective attribute in the analysis 
(Mouratidis, 2019). In a more recent study, Mouratidis (2020) used a wider set of variables describing the neighbourhood's socioeconomic structure and concluded that wellbeing measures are significantly associated with individual socio-demographics but not with the neighbourhood's socioeconomic profile or its urban form.

In their study of 1500 individuals in Hong Kong, Wang et al. (2019) controlled for population density and accessibility at the District Council Constituency Area level, but they did not find the variables statistically significant with respect to life satisfaction. They also controlled for a neighbourhood's socioeconomic characteristics and found that life satisfaction was higher among respondents living in neighbourhoods in which a greater share of people have a high level of education and where the majority of dwellings belonged to the public rental sector. Interestingly, they found that relative income (differences between respondents' household income and the median household income of their neighbourhood) is more important for wellbeing than absolute income (Wang et al., 2019).

Overall, research on the effect of context at the intra-urban scale has expanded in recent years, but the conclusions remain unclear, and the objective characteristics of a neighbourhood have been less important than the perceived qualities of a neighbourhood in people's survey questionnaire responses. Also, most of the studies, with the exception of the one done by Ala-Mantila et al. (2018), have used data from a single city, which hampers the generalizability of their conclusions. All in all, especially the relationship between SWB and the socioeconomic structure of the neighbourhood, both at an absolute and relative level, requires further research.

Therefore, our contribution to the neighbourhood characteristics and SWB research is twofold. First, we examine both the subjective and objective measures of a neighbourhood's characteristics, including contextual data at the postal code level on the socioeconomic attributes of a neighbourhood (level of unemployment, share of rental housing, share of low income households, share of those with a tertiary education and population density) and subjectively evaluated indicators on the quality of a neighbourhood (overall satisfaction with one's living conditions, distance to health and other services, disturbances caused by traffic or noise, safety and quality of public transport). Second, we used survey data from more than 26,000 respondents within a single country to shed light on general patterns in the association between neighbourhood characteristics and individual SWB instead of doing a case study of a single city in a region.

\section{Methodology and Data}

\subsection{FINSOTE Survey}

The National FinSote Survey is a study of health, wellbeing and the use of social services among the adult Finnish population aged 20 years and upwards. The study has been conducted since 2017 by the Finnish Institute for Health and Welfare (THL). Survey data is collected by a self-administered paper and online questionnaire available in Finnish, English, Swedish and Russian. The dataset used in this study was collected between October 2017 and March 2019. The sampling method consisted of a stratified random sampling design with 18 strata, one for every region (NUTS3 level) in Finland. The sample size for each region (NUTS3 level) was 3300 individuals/region (2300 in age group 20-74 years and 1000 in age group over 75 years) and a total response rate for the whole survey was $43 \%$. To correct for population representativeness of the survey data, weights were 
constructed for the analysis. The inverse probability weighting (IPW) method was used to account for the effects of missing data. With logistic regression, independent variables include register-based age, gender, marital status, language, education and region. The model was selected using the Bayesian information criterion. The IPW method improves the accuracy of studies done on the Finnish population (Härkänen et al., 2014). After excluding those observation from the dataset which were not possible to link to postal code we ended up with 26,422 observations for the analysis.

Due to regionally stratified sampling procedure the Finsote dataset has a good coverage across the land area in Finland and thus distribution of $\mathrm{N}$ in postal code areas. The average $\mathrm{N}$ in postal code area is 40.26 and only $4.2 \%$ of respondents are located in postal code areas with only one respondent and correspondingly $22.5 \%$ in postal code area with less than 10 respondents (see Appendix 2). Hence, these figures make the dataset suitable for MLM analysis as the methodological literature in MLM (Maas \& Hox, 2005) notes that distribution of observations within groups in not a key issue and only a small sample size $(\mathrm{N}<50)$ at level two (here postal code areas of which we have over 3000) leads to biased estimates (also see Hox \& McNeish, 2020).

\subsection{Indicators}

\subsubsection{Dependent Variable: Quality of Life (QoL)}

In aligning our study with the existing literature on "geography of happiness", we focused on the evaluative measure of subjective wellbeing. The corresponding survey item for this dimension in the FinSote survey is a single item measuring perceived QoL that follows the WHOQOL-BREF wording provided by the World Health Organization (WHO). Therefore, in this study perceived QoL was measured based on the following question: How would you rate your quality of life? Response options ranged from $1=$ very poor or $2=$ poor to $3=$ neither poor nor good, $4=$ good or $5=$ very good.

\subsubsection{Urbanity}

The level of urbanity indicator used in this analysis was based on an urban-rural classification system constructed by the Finnish Environment Institute (SYKE). The classification system provides a detailed description of living environment that is independent of municipal boundaries or other administrative borders. SYKE's urban-rural classification scheme divided the land area of Finland into 250 X $250 \mathrm{~m}$ statistical squares, which it then divided into seven classes according to their position in the urban-rural gradient. The classes were defined using GIS data on population, labour, commute and buildings as well as DIGIROAD road network data and Corine Land Cover data. A detailed description of the classification system, which was recently renewed in 2018, can be accessed from SYKE's website (SYKE, 2021).

As the Finsote survey contains an exact location indicator for each respondent in the form of a postal address, the data was converted into GPS coordinates and then linked to corresponding data on urban-rural classifications based on the $250 \times 250$ grid. The data was then treated as an individual-level indicator in the analysis. In analysis, the class "Local centres in rural area" was defined as reference category for being the the middle category in the seven-class scheme. 


\subsubsection{Mental Health Indicators}

The primary mental health measure used in the FinSote survey was the Mental Health Inventory (MHI-5) questionnaire. Three questions in the MHI-5 aim to identify depression symptoms and measure psychological wellbeing and two questions aim to measure symptoms of anxiety (Cuijpers et al., 2009). In psychiatry research, the MHI-5 questionnaire has been proven to exhibit good psychometric properties as an instrument for detecting anxiety and depression symptoms. In addition to the MHI-5, we also included a single item measure on perceived loneliness ("Do you ever feel lonely?": $1=$ never; 2 = very rarely; $3=$ sometimes; $4=$ fairly often; $5=$ all the time).

\subsubsection{Neighbourhood Characteristics (Postal Code Level)}

The objective neighbourhood-level variables examined in this analysis were obtained from the Paavo postal code area statistics database constructed and maintained by Statistics Finland (2021). The Paavo open database contains information on population structure, level of education, the income of the inhabitants and households, the size of households and their life stage, buildings and dwellings, workplaces and the main activities of the inhabitants. Based on available indicators in the Paavo database, the six most relevant postal code variables on the socioeconomic composition of areas were calculated for this analysis: share (\%) of unemployed out of total population, share (\%) of rental tenures out of total apartments, share $(\%)$ of population with a tertiary education out of total population over 18 years of age, share $(\%)$ of households in the lowest income tertile and population density (residents/10m2) of the postal code area. All measures were from 2018, except for the share of households in the lowest income tertile, where data was available only from 2017.

Postal codes in Finland can be considered a reasonably good proxy for describing a neighbourhood, as they are in general relatively small in size, compared to many similar international administrative units (e.g. zip codes in U.S. context or NUTS regions in EU) used in research purposes as well. In the whole country, the average number of inhabitants inside postal code is 1802 and the average area is $112 \mathrm{~km} 2$. However, in our sample, the more urban areas are pronounced, meaning the number of inhabitants is somewhat higher and area even smaller - thus using them to describe the neighbourhood is in well justified. Furthermore, postal code level is the smallest available spatial unit in Finland where contextual data on socioeconomic composition is available (from Paavo database) enabling hierarchical analysis.

\subsubsection{Individual Housing and Neighbourhood Satisfaction}

Living conditions in a respondent's neighborhood were assessed via the following question: "Does any of the following occur near your home, and if so, to what extent does it bother you?" The seven neighbourhood characteristics evaluated for the study included the following: dangerous intersections and/or traffic routes; slippery pedestrian pathways in winter; poorly lit traffic routes/roads and pathways; noise, smell or dust caused by traffic or industry; long distances to health services; long distances to other services (e.g. shops); and poor public transport. The response options for each question were $1=$ no; $2=$ yes, but it does not bother me; $3=$ it bothers me slightly; and $4=$ it bothers me a lot. In addition these items, we also included a single item on overall housing condition with the question "How satisfied are you with the 
conditions of your living place?" The responses ranged from $1=$ very dissatisfied or $2=$ dissatisfied to $3=$ neither satisfied nor dissatisfied, $4=$ satisfied or $5=$ very satisfied.

\subsubsection{Accessibility Indicators}

To examine the role of accessibility in relation to perceived QoL, we constructed two measures, distance to closest urban locality and distance to the capital city of Helsinki (postal code 00100). The distances (in $\mathrm{km}$ ) were calculated from the centre of each postal code area; for the distance to the closest urban locality, we relied on SYKE's classification of urban centres and localities.

\subsubsection{Socioeconomic Controls}

Based on the existing literature on SWB, we included standard individual socioeconomic and demographic variables available from the FinSote survey. Thus, as socioeconomic controls we included indicators for respondent's age, gender, years of education, marital status and housing (living alone) status, as well as dummy variable on a respondent's employment status. Unfortunately, the Finsote survey does not include a measure of household or individual income, but in analytical terms inclusion of measures of education and employment status serves as an adequate proxy for one's income.

\subsection{Method}

Due to the hierarchical design of our study, with individuals being nested in specific postal code areas, we derived our estimations using multilevel models, and more specifically, twolevel random intercept models. The equation for perceived quality of life as a function of level of urbanity, neighbourhood characteristics, accessibility, mental health, housing and neighbourhood satisfaction, and individual-level control variables can be expressed as follows (for individual $i$ in postal code area $j$ ):

$$
\begin{aligned}
\text { QoL }_{i j}= & \beta_{0 j}+\beta_{1} * \text { urbanity }_{i j}+\beta_{2} * \text { neighbourhood }_{j}+\beta_{3} * \text { accessibility }_{j} \\
& +\beta_{4} * \text { mental_health } \\
& +\beta_{5} * \text { neighbourhood_satisfaction } \\
& + \text { individual }- \text { level_control_variables }+e_{i j}
\end{aligned}
$$

The estimations were conducted by using the random intercept models, Stata version 16.1 and the meglm procedure, which has been designed for fitting multilevel mixed-effects generalized linear models into hierarchical datasets. Additionally, we applied the svy prefix command in Stata, which makes it possible to run statistical models for complex survey data and assign a weight specification for all levels in the hierarchical analysis. Individual weights in FinSote were applied in all models to correctly account for the effects of non-random missing data in the sampling procedure. The higher level weights were constructed by dividing the population in each postal code area by the corresponding number of respondents in the FinSote survey, and we scaled the mean of the postal code weight variable to one. Concerning missing values in the dataset we excluded cases listwise resulting a small decrease of observations when new variables are included to the model. 


\section{Results}

The descriptive statistics for the categorical and continuous variables used in the analysis are presented below in Tables 1 and 2, followed by the results of the hierarchical regression analysis in Table 3.

First, we included the three main geographical variables separately in Models 1, 2, and 3 in Table 3 to define their bivariate association with the dependent variable, individual QoL. Model 1 shows that living in a suburban environment (outer urban and peri-urban areas) is associated with higher QoL. As the model does not include socioeconomic controls, which are known to be strong predictors of QoL, and while it is also known that populations living in urban and suburban areas with detached housing are usually better educated and with higher incomes, these results are as expected. Our assumptions are supported by the results from Model 2, which includes neighbourhood characteristics at the postal code level as predictors of individual QoL. The results from Model 2 show that the share $(\%)$ of unemployed persons in a postal code area is a negative predictor of individual QoL, whereas the share (\%) of the population with a tertiary education is associated with higher QoL. The accessibility indicators in Model 3 show a negative but rather modest (Coeff. - 0.001) association with distance to urban locality and individual QoL.

Model 4 includes all the above-mentioned variables to the model, showing that in addition to the shares $(\%)$ of unemployed persons and those with a tertiary education retaining their significance, the share (\%) of rental tenures is also a modest positive predictor of QoL. Level of urbanity and accessibility indicators become insignificant. However, after also introducing the individual-level controls in Model 5, the effects of unemployment and education rates appear robust, but living in inner urban areas also emerged as significant and negative predictors of individual QoL. This result is very much in line with classic theses in urban sociology suggesting that a negative SWB affects urban and especially inner-city living. Consequently, drawing from Simmelian theories, the main suspect for lower SWB in urban surroundings is the relative lower mental health moderated by the urban environment; thereby, Model 6 includes mental health (MHI-5) indicators as well as perceived loneliness in the model. As expected, MHI-5 indicators and loneliness serve as predictors of QoL and controlling for these measures causes the effects of living in an inner urban area to become insignificant. In other words, mental health and loneliness account for relatively lower QoL in inner urban areas in the previous model. Interestingly, the share (\%) of those unemployed also loses its significance after including MHI-5 and loneliness indicators, while the share (\%) of those with a tertiary education is still a robust predictor of QoL. Finally, Model 7 also includes indicators on individual housing and neighbourhood satisfaction in the model, demonstrating that overall satisfaction for housing conditions is a positive predictor of QoL, while being bothered by slippery pedestrian pathways in the winter and long distances to health and other services is associated with relatively lower QoL. With respect to the objective geographical variables, here the effect of the share (\%) of those with a tertiary education in a postal code area remains robust, but interestingly, once subjective neighbourhood characteristics are controlled for, then living in rural area close to an urban area becomes a positive and significant predictor of individual QoL.

As robustness check, we ran the final model (Model 7 in Table 3) with two alternative specifications. First, due to the ordinal nature of our dependent variable, the perceived QoL on a five-point scale, we also derived estimations using multilevel mixedeffects ordered logistic regression model (meologit in STATA). Second, we also ran the models with equal (1) weight for all postal code areas. Regarding the first check, all 
Table 1 Descriptive statistics of categorical variables

\begin{tabular}{|c|c|c|c|}
\hline & Freq & Percent & Cum \\
\hline \multicolumn{4}{|l|}{ Dependent variable } \\
\hline \multicolumn{4}{|l|}{ Perceived quality of life } \\
\hline Very poor & 218 & 0.84 & 0.84 \\
\hline Poor & 1348 & 5.20 & 6.04 \\
\hline Neither poor nor good & 7687 & 29.63 & 35.66 \\
\hline Good & 13,281 & 51.19 & 86.85 \\
\hline Very good & 3411 & 13.15 & 100.00 \\
\hline Total & 25,945 & 100.00 & \\
\hline \multicolumn{4}{|l|}{ Socioeconomic variables } \\
\hline \multicolumn{4}{|l|}{ Age group } \\
\hline $20>$ & 2498 & 9.45 & 9.45 \\
\hline $35>$ & 4373 & 16.55 & 26.00 \\
\hline $55>$ & 4507 & 17.06 & 43.06 \\
\hline $65>$ & 5263 & 19.92 & 62.98 \\
\hline $75>$ & 9781 & 37.02 & 100.00 \\
\hline Total & 26,422 & 100.00 & \\
\hline \multicolumn{4}{|l|}{ Marital status } \\
\hline Married or in a registered relations & 13,905 & 53.83 & 53.83 \\
\hline Cohabiting & 3107 & 12.03 & 65.86 \\
\hline Separated or divorced & 2179 & 8.44 & 74.3 \\
\hline Widowed & 3735 & 14.46 & 88.76 \\
\hline Single & 2904 & 11.24 & 100.00 \\
\hline Total & 25,830 & 100.00 & \\
\hline \multicolumn{4}{|l|}{ Living alone } \\
\hline Yes & 7905 & 30.58 & 30.58 \\
\hline No & 17,949 & 69.42 & 100.00 \\
\hline Total & 25,854 & 100.00 & \\
\hline \multicolumn{4}{|l|}{ Unemplued or laid off } \\
\hline No & 25,731 & 97.38 & 97.38 \\
\hline Yes & 691 & 2.68 & 100.00 \\
\hline Total & & 100.00 & \\
\hline \multicolumn{4}{|l|}{ Urban rural classification } \\
\hline Inner urban area & 6375 & 24.20 & 24.20 \\
\hline Outer urban area & 6698 & 25.42 & 49.62 \\
\hline Peri-urban area & 2578 & 9.79 & 59.41 \\
\hline Local centres in rural area & 1855 & 7.04 & 66.45 \\
\hline Rural areas close to urban areas & 2084 & 7.91 & 74.36 \\
\hline Rural heartlands areas & 4095 & 15.54 & 89.90 \\
\hline Sparsely populated rural areas & 2661 & 10.10 & 100.00 \\
\hline Total & 26,346 & 100.00 & \\
\hline \multicolumn{4}{|l|}{ Gender } \\
\hline Male & 11,507 & 43.55 & 43.55 \\
\hline Female & 14,915 & 56.45 & 100.00 \\
\hline Total & 26,422 & 100.00 & \\
\hline
\end{tabular}


Table 2 Descriptive statistics of continuous variables

\begin{tabular}{|c|c|c|c|c|c|}
\hline & Obs & Mean & SD & Min & Max \\
\hline \multicolumn{6}{|l|}{ Neighbouhood characteristics (postal code level) } \\
\hline Share (\%) of unemployed from total population, 2018 & 2267 & 6.7 & 2.205 & 0 & 27.1 \\
\hline Share $(\%)$ of rental tenures from total apartments & 2035 & 29.0 & 17.094 & 0 & 100 \\
\hline $\begin{array}{l}\text { Share }(\%) \text { of population with tertiary aducation from total popu- } \\
\text { lation over } 18 \text { years, } 2018\end{array}$ & 2221 & 8.10 & 5.235 & 0 & 44.0 \\
\hline $\begin{array}{l}\text { Share (\%) of households belonging to the lowest income tertile, } \\
2017\end{array}$ & 2252 & 27.8 & 8.431 & 2.7 & 64.1 \\
\hline Population density (residents/10m2) & 3009 & .6 & 1.227 & 0 & 21.2 \\
\hline \multicolumn{6}{|c|}{ Accessibility indicators (calculated from centroids of each postal code area) } \\
\hline Distance $(\mathrm{km})$ to nearest urban locality & 26,421 & 23.6 & 28.90 & 0.025 & 354.4 \\
\hline Distance $(\mathrm{km})$ to the capital Helsinki (postal code 00,100 ) & 26,421 & 282.8 & 174.86 & 0 & 1069.0 \\
\hline \multicolumn{6}{|l|}{ Socioeconomic variables } \\
\hline Number of years in education & 24,265 & 12.294 & 4.491 & 0 & 90 \\
\hline \multicolumn{6}{|l|}{ Individual mental health varibles ${ }^{\mathrm{a}}$} \\
\hline Loneliness & 25,941 & 2.125 & .949 & 1 & 5 \\
\hline "Very nervous" & 24,764 & 5.241 & .902 & 1 & 6 \\
\hline "In such a low mood that nothing could cheer you up" & 24,595 & 5.480 & .881 & 1 & 6 \\
\hline "Calm and peaceful" & 25,119 & 2.597 & 1.245 & 1 & 6 \\
\hline "Downhearted and sad" & 24,640 & 5.136 & .993 & 1 & 6 \\
\hline "Happy" & 25,030 & 2.741 & 1.282 & 1 & 6 \\
\hline \multicolumn{6}{|l|}{ Individual housing and neighbourhood satisfaction ${ }^{\mathrm{b}}$} \\
\hline Overall satisfaction to ones living place & 25,856 & 4.023 & .827 & 1 & 5 \\
\hline Dangerous intersections and/or traffic routes & 25,640 & 1.695 & .822 & 1 & 4 \\
\hline Slippery pedestrian path in winter & 25,708 & 2.435 & .914 & 1 & 4 \\
\hline Poorly lit traffic routes/roads and paths & 25,501 & 1.865 & .97 & 1 & 4 \\
\hline Noise, smell of dust caused by traffic or industry & 25,657 & 1.666 & .858 & 1 & 4 \\
\hline Long distances to health services & 25,708 & 1.669 & .937 & 1 & 4 \\
\hline Long distances to other services (e.g. shops) & 25,766 & 1.548 & .864 & 1 & 4 \\
\hline Poor public transport & 25,628 & 2.013 & 1.058 & 1 & 4 \\
\hline
\end{tabular}

a As a response to question ""Over the past 4 weeks, for how much of the time have you felt:" 1: Not at all; 2: A little fo time; 3: Some of the time; 4: a good bit of the time; 5: Most of the time; 6: All of the time

${ }^{\mathrm{b}}$ As a response to question Does any of the following occur near your home, and if so, to what extent does it bother you. 1: No; 2: Yes, but it does not bother me; 3: It bothers me slightly; 4: It bothers me a lot

geographical variables in the final model (living in a rural area close to an urban area and share of population with a tertiary education) retained their direction and statistical significance. Likewise, the second robustness check with equal postal code weights (all areas weighted as 1) did not alter the significance of coefficients, but additionally the share $(\%)$ of unemployed out of the total population in a postal code area emerged as a negative predictor (Coeff. -0.008 p. 0.008) of perceived QoL and distance to nearest urban centre as a positive predictor (Coeff. 0.006 p. 0.026) of perceived QoL. None of the mental health or housing and neighbourhood satisfaction variables were altered by the robustness checks. 


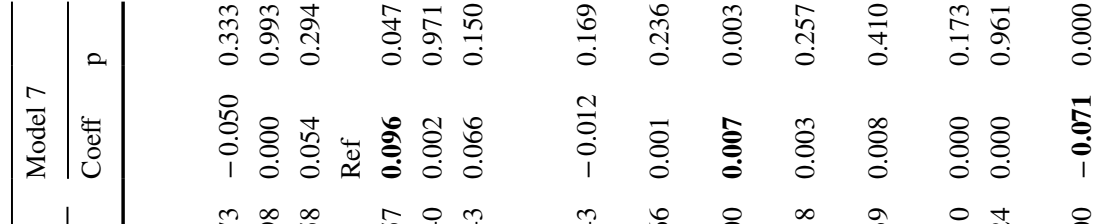

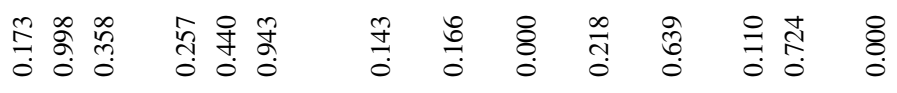

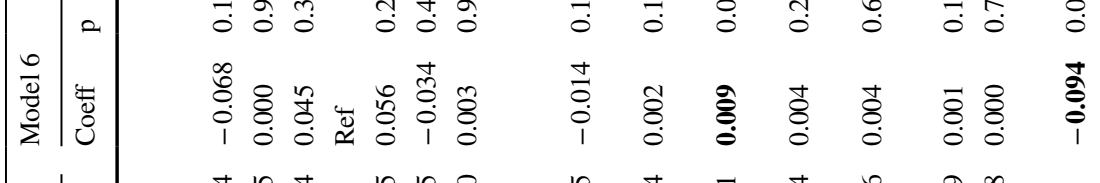

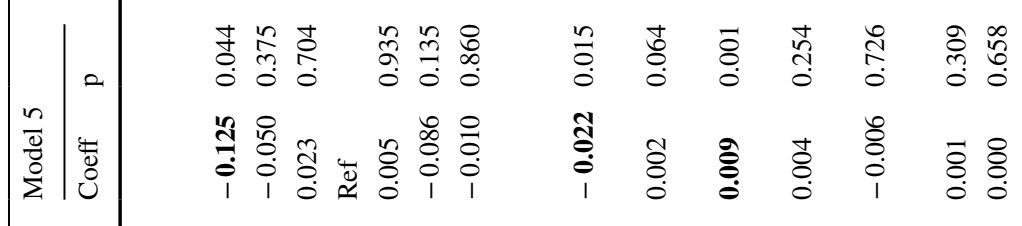

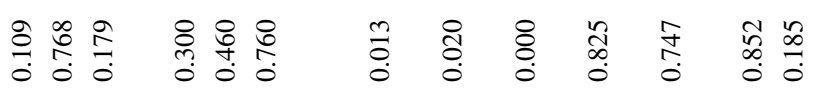

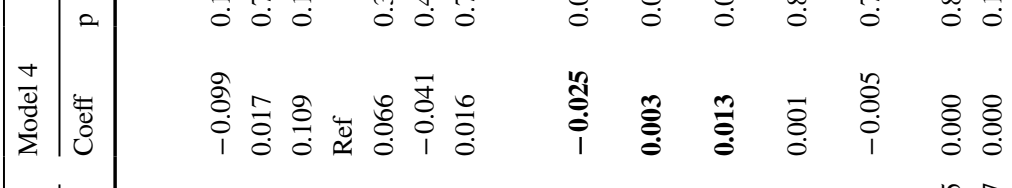

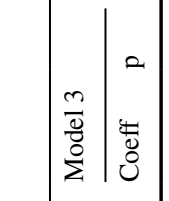

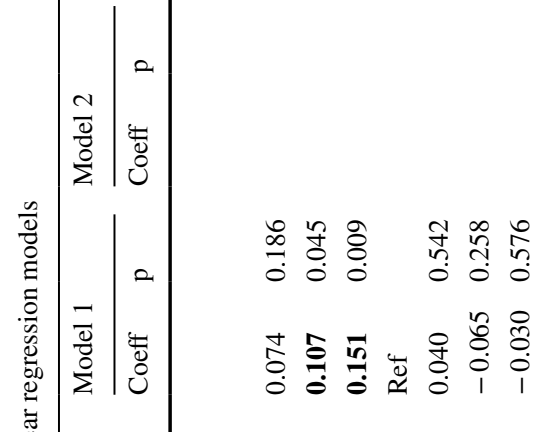

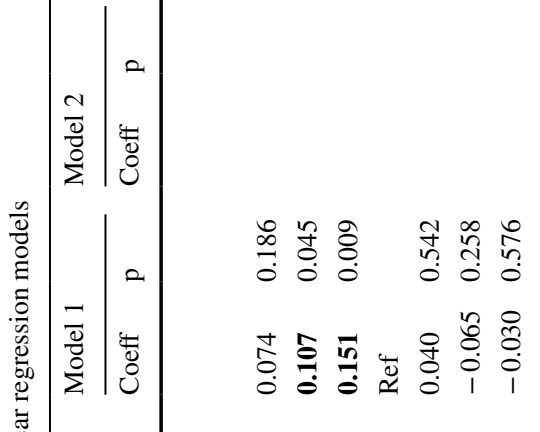

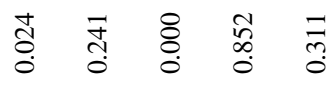

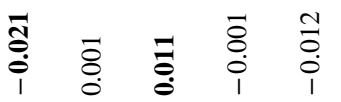

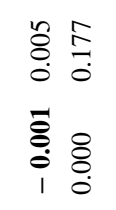




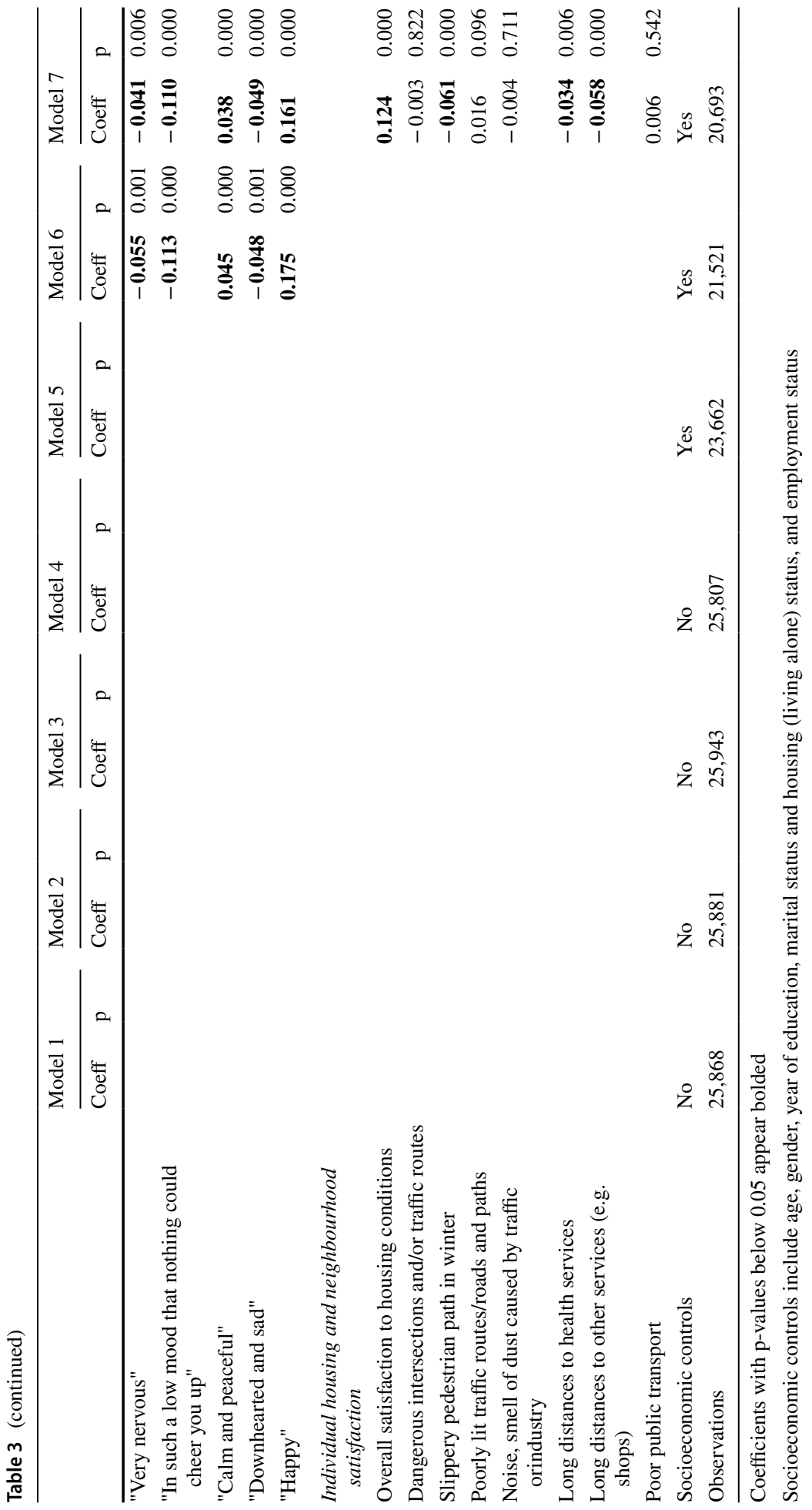




\section{Conclusion and Discussion}

This analysis has evaluated three specific themes within the "geography of happiness" literature: level of urbanity, role of neighborhood characteristics and accessibility to (urban) services and amenities as predictors of individual subjective wellbeing (SWB). We addressed the questions by applying a novel dataset that included an exact measure of the level of urbanity of respondents' living environments derived from a $250 \times 250 \mathrm{~m}$ grid, indicators of respondents' socioeconomic status (e.g. share of those unemployed and with a tertiary education) based on postal code area as well as indicators of physical distance to the nearest urban locality and capital city. We examined the role of these theoretically overlapping, but empirically distinct, different measures on urbanity as predictors of individual-level Quality of life (QoL). We approached the questions by acknowledging the hierarchical nature of the dataset and thus applying a Multilevel modelling (MLM) method, which made it possible for us to differentiate between the contextual effects at the postal code level and individual-level characteristics.

Our empirical analysis showed that while suburban residence (outer urban and peri-urban areas) are associated with higher QoL in unadjusted models, when controlling for socioeconomic factors living in an inner urban area or in a neighbourhood (postal code area) with a high unemployment rate are associated with lower lower QoL. Additionally, the share of those with a tertiary education in a neighbourhood has a positive effect on QoL, which is robust concerning individual mental health measures as well as housing and neighbourhood satisfaction. The effects of inner urban living (based on a 250 X $250 \mathrm{~m}$ grid) as well as the unemployment rate of a neighbourhood became insignificant predictors of QoL when controlling for mental health measures and perceived loneliness. Finally, after also accounting for individually evaluated neighbourhood characteristics, including subjectively assessed accessibility to health and other services, living a rural area close to an urban core emerged as positive predictor of QoL.

In sum, these results confirm and add more detail to earlier findings on urban-rural differences in SWB. First, our analysis shows that the negative effect of urban living is specific to the inner urban core area. Second, the framework and results of our analysis highlight the importance of socioeconomic controls (individual-level attributes are known to relate to level of SWB) when examining the urban-rural differences in SWB. In other words, and when using MLM vocabulary, the potential contextual effect of urban context is "lurking" behind the compositional effect related to socioeconomic attributes or urban and suburban population. Third, we related the negative effect of urban core living to the established psychometric measures of mental health (Mental Health Inventory, MHI-5) and perceived loneliness, thereby providing the most detailed empirical support to date for Simmel's (1903) classic thesis that urban (inner city) life is characterized by nervousness, anxiety and sentiments of loneliness.

Additionally, the extensive set of measures for urbanity and accessibility in this study enabled us to address a more recent thesis proposed by Lenzi and Perucca $(2016,2020)$ that a city's positive externalities may expand beyond the urban boundaries. Hence, Lenzi and Perucca $(2016,2020)$ argued that the optimal location in terms of higher SWB would be living in rural areas embedded in urbanized regions and having access to various urban amenities. Our analysis provides support for such a claim, as our final model shows that living in a rural area close to an urban areas emerged as a positive predictor of individual QoL. However, it needs to be noted that as we controlled for objective distance (in $\mathrm{km}$ ) to urban localities and also subjectively assessed accessibility to health and other services, the positive relationship between living in a rural area close to an urban core and QoL needs to be explained by other mechanisms than simple proximity to the amenities provided by the largest urban agglomerations, as suggested by Lenzi and Perucca (2020). 
Another area within the "geography of happiness" literature to which this analysis makes a contribution is the question of what neighbourhood characteristics shape individual SWB. Our analytical setting and extensive dataset covering the whole Finland and including both objective (contextual postal code data) and subjective (individually evaluated housing and neighbourhood satisfaction) measures provided a rather novel evidence of the contextual effects for individual QoL. Our finding on the association between the share of persons with a tertiary education in a neighbourhood and QoL is an important finding and serves as a key area for future "geography of happiness" research and the debate on related "neighborhood effects" in urban studies (e.g. Sampson, 2019). Possible explanations for the link between the two include, for example, a certain status effect of living in highly educated neighbourhoods. Additionally, the contextual negative SWB effect of living in a neighbourhood with high levels of unemployment could be related to discussions in urban studies on social stigma, disorder and security (e.g. Kemppainen \& Saarsalmi, 2015).In sum, our findings on the socioeconomic attributes of neighbourhoods and QoL is an area where further research is needed, and empirical analyses on the geography of SWB within a city or region should be conducted in accordance with theoretically diligent urban studies.

Despite these clear contributions to the existing literature, this analysis is nonetheless subject to certain limitations that can be seen as future points of reference. First, no direct causality can be confirmed as a result of our cross-sectional setting. In other words, the observed geographical could be explained the by compositional effects related to certain omitted variable. In technical terms, the observed negative QoL effect of living in urban core areas could be due to spatial sorting pattern where the inherently depressed and lonely individuals self-select themselves to urban areas. However, our empirical analysis was conducted under the theoretical framing (e.g. Simmel, 1903) that assume causal order from urban living to individual SWB which we find more plausible. Nonetheless, it is clear that future analyses should seek to collect panel datasets on SWB that would make it possible to track individuals through time and different living environments.

One of the possible ways to address these limitations may be to encourage researchers focused on "geography of happiness" to engage in transdisciplinary articles and projects between social sciences and environmental and neural psychology. There exists a great potential in analyses that would be able to merge - both theoretically and empirically - both cultural (e.g. Simmel, 1903) and neuropsychological explanations (e.g. (Lederbogen et al, 2011; Peen et al., 2010) for urban-rural SWB differences. Likewise, the insights of such transdisciplinary scrutinized knowledge would bear central importance for policy makers not only in urban planning and architecture but also in broader regional, housing, and (counter)urbanization policies.

Finally, it needs to acknowledged that country specific analyses such as this are always subject to generalization question regarding their findings. As noted in the introduction this analysis focused on spatial differences in QoL within the happiest country in the world. Results confirm that robust urban-rural differences do exist in such context but we are left which a question on which country level attributes are related to emergence of such patterns in a country (see also Sørensen, 2021; Weckroth \& Kemppainen, 2021). Thus, future analyses should try to detect and construct datasets that enable replicating this study in other national and most preferably international framings.

As conclusion, regardless of these limitations, some policy recommendations can be derived from the results of this study. First, the most obvious policy recommendation is related to the main effects of housing and neighbourhood variables. Perhaps a bit surprisingly being bothered by slippery pedestrian pathway in winter is significant predictor for 
lower QoL, which provides a simple policy recommendation for urban planning and maintenance, at least in the Nordic context. A bit broader policy recommendation can be derived from the negative QoL effect of long distances to health and other services, which relates to urban and regional planning and more generally to the spatial form of communities.

Finally, even broader and highly topical issue is related to regional policies driven by increasing urbanization and rural-urban migration patterns. As a whole, the results of this analysis question urbanization as spatial process that necessarily leads to higher quality of life. The results also resonate with housing preference research in Finnish context noting a persistent affection for living in a detached housing located outside but in a proximity of a city. These remarks are also in line with the causes of the current Covid19 pandemic, which have motivated a number of people to prefer relocating in more rural surroundings, at least those segments of the population who have the opportunity for telecommuting.

\section{Appendix 1}

See Table 4.

Table 4 Efficients for individual socioecnomic variables from hierarchical Linear Regression model

\begin{tabular}{lll}
\hline Variable & Coeff. & p-value \\
\hline Gender & & \\
Male & Ref. & \\
Female & $\mathbf{0 . 0 7 8}$ & 0.000 \\
Age group & & \\
$20>$ & Ref. & \\
$35>$ & $\mathbf{- 0 . 0 8 9}$ & 0.000 \\
$55>$ & $\mathbf{- 0 . 2 0 0}$ & 0.000 \\
$65>$ & $\mathbf{- 0 . 3 0 2}$ & 0.000 \\
$75>$ & $\mathbf{- 0 . 4 7 4}$ & 0.000 \\
Education & & \\
Number of years in education & $\mathbf{0 . 0 2 3}$ & 0.000 \\
Marital status & & \\
Married or in a registered relations & Ref. & \\
Cohabiting & $\mathbf{- 0 . 0 5 3}$ & 0.032 \\
Separated or divorced & $\mathbf{- 0 . 0 9 1}$ & 0.022 \\
Widowed & $\mathbf{- 0 . 0 9 1}$ & 0.043 \\
Single & $\mathbf{- 0 . 1 1 6}$ & 0.005 \\
Living alone & & \\
No & Ref. & \\
Yes & -0.012 & 0.772 \\
Unemployed or laid of & & \\
No & Ref. & \\
Yes & $\mathbf{- 0 . 2 2 7}$ & 0.001 \\
Observations & 20,693 & \\
\hline & &
\end{tabular}

Coefficients with p-values below 0.05 appear bolded

Coefficients are from full model (7) in Table 3) 


\section{Appendix 2}

See Table 5.

Table 5 Distribution of respondents in Postal code areas in the data

\begin{tabular}{|c|c|c|c|}
\hline $\begin{array}{l}\mathrm{N} \text { in postal code } \\
\text { area }\end{array}$ & Frequency & Percent & $\begin{array}{l}\text { Cumu- } \\
\text { lative } \\
\text { percent }\end{array}$ \\
\hline 1 & 1122 & 4.2 & 4.2 \\
\hline 2 & 720 & 2.7 & 6.8 \\
\hline 3 & 735 & 2.7 & 9.5 \\
\hline 4 & 668 & 2.5 & 12.0 \\
\hline 5 & 680 & 2.5 & 14.5 \\
\hline 6 & 630 & 2.3 & 16.8 \\
\hline 7 & 455 & 1.7 & 18.5 \\
\hline 8 & 520 & 1.9 & 20.4 \\
\hline 9 & 450 & 1.7 & 22.1 \\
\hline 10 & 430 & 1.6 & 23.7 \\
\hline 11 & 407 & 1.5 & 25.2 \\
\hline 12 & 372 & 1.4 & 26.6 \\
\hline 13 & 455 & 1.7 & 28.3 \\
\hline 14 & 546 & 2.0 & 30.3 \\
\hline 15 & 300 & 1.1 & 31.4 \\
\hline 16 & 496 & 1.8 & 33.2 \\
\hline 17 & 442 & 1.6 & 34.9 \\
\hline 18 & 342 & 1.3 & 36.1 \\
\hline 19 & 361 & 1.3 & 37.4 \\
\hline 20 & 460 & 1.7 & 39.1 \\
\hline 21 & 399 & 1.5 & 40.6 \\
\hline 22 & 308 & 1.1 & 41.8 \\
\hline 23 & 391 & 1.5 & 43.2 \\
\hline 24 & 384 & 1.4 & 44.6 \\
\hline 25 & 600 & 2.2 & 46.8 \\
\hline 26 & 520 & 1.9 & 48.8 \\
\hline 27 & 297 & 1.1 & 49.9 \\
\hline 28 & 280 & 1.0 & 50.9 \\
\hline 29 & 377 & 1.4 & 52.3 \\
\hline 30 & 420 & 1.6 & 53.8 \\
\hline 31 & 496 & 1.8 & 55.7 \\
\hline 32 & 352 & 1.3 & 57.0 \\
\hline 33 & 264 & 1.0 & 58.0 \\
\hline 34 & 272 & 1.0 & 59.0 \\
\hline 35 & 280 & 1.0 & 60.0 \\
\hline 36 & 396 & 1.5 & 61.5 \\
\hline 37 & 259 & 1.0 & 62.4 \\
\hline 38 & 190 & 0.7 & 63.1 \\
\hline
\end{tabular}


M. Weckroth et al.

Table 5 (continued)

\begin{tabular}{|c|c|c|c|}
\hline $\begin{array}{l}\mathrm{N} \text { in postal code } \\
\text { area }\end{array}$ & Frequency & Percent & $\begin{array}{l}\text { Cumu- } \\
\text { lative } \\
\text { percent }\end{array}$ \\
\hline 39 & 468 & 1.7 & 64.8 \\
\hline 40 & 160 & 0.6 & 65.4 \\
\hline 41 & 82 & 0.3 & 65.7 \\
\hline 42 & 504 & 1.9 & 67.6 \\
\hline 43 & 129 & 0.5 & 68.1 \\
\hline 44 & 176 & 0.7 & 68.7 \\
\hline 45 & 225 & 0.8 & 69.6 \\
\hline 46 & 138 & 0.5 & 70.1 \\
\hline 47 & 235 & 0.9 & 70.9 \\
\hline 48 & 96 & 0.4 & 71.3 \\
\hline 49 & 196 & 0.7 & 72.0 \\
\hline 50 & 150 & 0.6 & 72.6 \\
\hline 51 & 408 & 1.5 & 74.1 \\
\hline 52 & 260 & 1.0 & 75.0 \\
\hline 53 & 53 & 0.2 & 75.2 \\
\hline 55 & 110 & 0.4 & 75.6 \\
\hline 56 & 224 & 0.8 & 76.5 \\
\hline 57 & 171 & 0.6 & 77.1 \\
\hline 58 & 116 & 0.4 & 77.5 \\
\hline 59 & 118 & 0.4 & 78.0 \\
\hline 60 & 180 & 0.7 & 78.6 \\
\hline 61 & 122 & 0.5 & 79.1 \\
\hline 62 & 248 & 0.9 & 80.0 \\
\hline 64 & 64 & 0.2 & 80.2 \\
\hline 65 & 130 & 0.5 & 80.7 \\
\hline 66 & 132 & 0.5 & 81.2 \\
\hline 67 & 67 & 0.3 & 81.5 \\
\hline 68 & 204 & 0.8 & 82.2 \\
\hline 69 & 276 & 1.0 & 83.2 \\
\hline 72 & 216 & 0.8 & 84.0 \\
\hline 75 & 75 & 0.3 & 84.3 \\
\hline 76 & 76 & 0.3 & 84.6 \\
\hline 77 & 77 & 0.3 & 84.9 \\
\hline 78 & 78 & 0.3 & 85.2 \\
\hline 79 & 79 & 0.3 & 85.5 \\
\hline 80 & 80 & 0.3 & 85.7 \\
\hline 81 & 81 & 0.3 & 86.0 \\
\hline 83 & 83 & 0.3 & 86.4 \\
\hline 84 & 84 & 0.3 & 86.7 \\
\hline 87 & 87 & 0.3 & 87.0 \\
\hline 88 & 88 & 0.3 & 87.3 \\
\hline 89 & 89 & 0.3 & 87.6 \\
\hline 90 & 90 & 0.3 & 88.0 \\
\hline 92 & 92 & 0.3 & 88.3 \\
\hline
\end{tabular}


Table 5 (continued)

\begin{tabular}{|c|c|c|c|}
\hline $\begin{array}{l}\mathrm{N} \text { in postal code } \\
\text { area }\end{array}$ & Frequency & Percent & $\begin{array}{l}\text { Cumu- } \\
\text { lative } \\
\text { percent }\end{array}$ \\
\hline 93 & 93 & 0.3 & 88.7 \\
\hline 94 & 94 & 0.4 & 89.0 \\
\hline 96 & 96 & 0.4 & 89.4 \\
\hline 98 & 294 & 1.1 & 90.4 \\
\hline 99 & 99 & 0.4 & 90.8 \\
\hline 101 & 101 & 0.4 & 91.2 \\
\hline 106 & 106 & 0.4 & 91.6 \\
\hline 107 & 214 & 0.8 & 92.4 \\
\hline 108 & 108 & 0.4 & 92.8 \\
\hline 109 & 218 & 0.8 & 93.6 \\
\hline 112 & 224 & 0.8 & 94.4 \\
\hline 116 & 116 & 0.4 & 94.8 \\
\hline 120 & 120 & 0.4 & 95.3 \\
\hline 127 & 254 & 0.9 & 96.2 \\
\hline 131 & 131 & 0.5 & 96.7 \\
\hline 158 & 158 & 0.6 & 97.3 \\
\hline 159 & 159 & 0.6 & 97.9 \\
\hline 161 & 161 & 0.6 & 98.5 \\
\hline 177 & 177 & 0.7 & 99.1 \\
\hline 240 & 240 & 0.9 & 100.0 \\
\hline Total & 26,422 & 100 & 100 \\
\hline
\end{tabular}

Funding Open access funding provided by Natural Resources Institute Finland (LUKE). The fundinging was grant by Ella ja Georg Ehrnroothin Säätiö.

Open Access This article is licensed under a Creative Commons Attribution 4.0 International License, which permits use, sharing, adaptation, distribution and reproduction in any medium or format, as long as you give appropriate credit to the original author(s) and the source, provide a link to the Creative Commons licence, and indicate if changes were made. The images or other third party material in this article are included in the article's Creative Commons licence, unless indicated otherwise in a credit line to the material. If material is not included in the article's Creative Commons licence and your intended use is not permitted by statutory regulation or exceeds the permitted use, you will need to obtain permission directly from the copyright holder. To view a copy of this licence, visit http://creativecommons.org/licenses/by/4.0/.

\section{References}

Ala-Mantila, S., Heinonen, J., Junnila, S., \& Saarsalmi, P. (2018). Spatial nature of urban well-being. Regional Studies, 52(7), 959-973.

Aitkin, M. A., \& Longford, N. T. (1986). Statistical modeling issues in school effectiveness studies. Journal of the Royal Statistical Society, 149, 1-43.

Aminzadeh, K., Denny, S., Utter, J., Milfont, T. L., Ameratunga, S., Teevale, T., \& Clark, T. (2013). Neighbourhood social capital and adolescent self-reported wellbeing in New Zealand: A multilevel analysis. Social Science and Medicine, 84, 13-21.

Arifwidodo, S. D. (2012). Exploring the effect of compact development policy to urban quality of life in Bandung, Indonesia City. Culture and Society, 3(4), 303-311. 
Aslam, A., \& Corrado, L. (2012). The geography of well-being. Journal of Economic Geography, 12, 627-649.

Ballas, D. (2013). What makes a 'happy city'? Cities, 32, S39-S50.

Ballas, D., \& Tranmer, M. (2012). Happy People or happy places? A multi-level modelling approach to the analysis of happiness and well-being. International Regional Science Review, 35, 70-102.

Berry, B. J., \& Okulizc-Kozaryn, A. (2011). An urban-rural happiness gradient. Urban Geography, 32(6), $871-883$.

Berry, J. L., \& Okulicz-Kozaryn, A. (2009). Dissatisfaction with city life: A new look at some old questions. Cities, 26(3), 117-124.

Brereton, F., Clinch, P., \& Ferreira, S. (2008). Happiness, geography, and the environment. Ecological Economics, 65(2), 386-396.

Burger, M. J., Morrison, P. S., Hendriks, M., et al. (2020). Urban-rural happiness differentials across the world. In J. F. Helliwell, R. Layard, J. Sachs, et al. (Eds.), World Happiness Report 2020 (pp. 63-93). Sustainable Development Solutions Network.

Cuijpers, P., Smits, N., Donker, T., ten Have, M., \& de Graaf, R. (2009). Screening for mood and anxiety disorders with the five-item, the three-item, and the two-item Mental Health Inventory. Psychiatry Research, 168(3), 250-255.

Cramer, V., Torgersen, S., \& Kringlen, E. (2004). Quality of life in a city: The effect of population density. Social Indicators Research, 69(1), 103-116.

Diener, E., Oishi, S., \& Tay, L. (2018). Advances in subjective well-being research. Nature Human Behaviour, 2, 253-260.

Donbavand, S. (2020). A Simmelian theory of structural loneliness. Journal for the Theory of Social Behaviour, Online First: https://doi.org/10.1111/jtsb.12263

Durkheim, E. (1893). The division of labour in society. Alcan.

Easterlin, R. A., Angelescu, L., \& Zweig, J. S. (2011). The impact of modern economic growth on urbanrural differences in subjective well-being. World Development, 39(12), 2187-2198.

Ettema, D., \& Schekkerman, M. (2016). How do spatial characteristics influence well-being and mental health? Comparing the effect of objective and subjective characteristics at different spatial scales. Travel Behaviour and Society, 5, 56-67.

Fernandez, R. M., \& Kulik, J. C. (1981). A multilevel model of life satisfaction: Effects of individual characteristics and neighborhood composition. American Sociological Review, 46(6), 840-850.

Helliwell, J., Layard, R., Sachs, J., \& De Neve, J. (Eds.). (2020). World happiness report 2020. Sustainable Development Solutions Network. Gallup World Poll.

Hoogerbrugge, M. M., Burger, M. J., \& Van Oort, F. G. (2021). Spatial structure and subjective well-being in north-west Europe. Regional Studies. https://doi.org/10.1080/00343404.2021.1873261

Hox, J, McNeish, D (2020), Small Samples in Multilevel Modelling, in Rens van de Schoot, Milica Miočević (eds), Small Sample Size Solutions: A Guide for Applied Researchers and Practitioners, Taylor and Francis, pp 215-225.

Härkänen, T., Kaikkonen, R., Virtala, E., \& Koskinen, S. (2014). Inverse probability weighting and doubly robust methods in correcting the effects of non-response in the reimbursed medication and selfreported turnout estimates in the ATH survey. BMC Public Health, 14, 1150.

Kemppainen, T., \& Saarsalmi, P. (2015). Perceived social disorder in suburban housing estates in the Helsinki region: A contextual analysis. Research on Finnish Society, 8, 47-60.

Knight, J., Song, L., \& Gunatilaka, R. (2009). Subjective well-being and its determinants in rural china. China Economic Review, 20(4), 635-649.

Kristjansson, K. (2010). Positive psychology, happiness, and virtue: The troublesome conceptual issues. Review of General Psychology, 14, 296-310.

Leckie, G. (2009). The complexity of school and neighbourhood effects and movements of pupils on school differences in models of educational achievement. Journal of the Royal Statistical Society: Series A, $172(3), 537-554$.

Lederbogen, F., Kirsch, P., Haddad, L., et al. (2011). City living and urban upbringing affect neural social stress processing in humans. Nature, 474, 498-501.

Lenzi, C., \& Perucca, G. (2016). Are urbanized areas source of life satisfaction? Evidence from EU regions. Papers in Regional Science, 97, 105-122.

Li, N. P., \& Kanazawa, S. (2016). Country roads, take me home ... to my friends: How intelligence, population density, and friendship affect modern happiness. British Journal of Psychology, 107(4), 675-697.

Maas, C., \& Cox, J. (2005). Sufficient sample sizes for multilevel modeling. Methodology, 1(3), 86-92.

Michalos, A.C. (2014). Quality of life, satisfaction with. In A.C. Michalos (Ed), Encyclopedia of quality of life and well-being research. Springer, Dordrecht. https://doi.org/10.1007/978-94-007-0753-5_2379 
Morrison, P. S. (2011). Local expressions of subjective well-being: The New Zealand experience. Regional Studies, 45(8), 1039-1054.

Morrison, P. S., \& Weckroth, M. (2018). Human values, subjective well-being and the metropolitan region. Regional Studies, 52(3), 325-337.

Mouratidis, K. (2019). Compact city, urban sprawl, and subjective well-being. Cities, 92, 261-272.

Mouratidis, K. (2020). Neighborhood characteristics, neighborhood satisfaction, and well-being: The links with neighborhood deprivation. Land Use Policy, 99, 104886.

OECD. (2013). How's life? 2013: Measuring well-being. OECD Publishing. Online Source: https://doi.org/ 10.1787/9789264201392-en

Okulicz-Kozaryn, A. (2017). Unhappy metropolis (when American city is too big). Cities, 61, 144-155.

Okulicz-Kozaryn, A., Valente, R. (2020). The perennial dissatisfaction of urban upbringing. Cities, 104.

Owen, G., Harris, R., \& Jones, K. (2016). Under examination: Multilevel models, geography and health research. Progress in Human Geography, 40, 394-412.

Peen, J., Schoevers, R., Beekman, A., \& Dekker, J. (2010). The current status of urban-rural differences in psychiatric disorders. Acta Psychiatrica Scandinavica, 121, 84-93.

Piper, A. T. (2014). Europe's capital cities and the happiness penalty: An investigation using the European social survey. Social Indicators Research, 123, 103-126.

Pittau, M., Zelli, R., \& Gelman, A. (2010). Economic disparities and life satisfaction in European regions. Social Indicators Research., 96, 339-361.

Requena, F. (2016). Rural-urban living and level of economic development as factors in subjective wellbeing. Social Indicators Research, 128(2), 693-708.

Savage, M., Ward, K., \& Warde, A. (2003). Urban sociology, capitalism and modernity (2nd ed.). Palgrave Macmillan.

Shucksmith, M., Cameron, S., Merridew, T., \& Pichler, F. (2009). Urban-rural differences in quality of life across the European Union. Regional Studies, 43, 1275-1289.

Simmel, G. (1903). The metropolis and mental life. Free Press.

Sampson, R. (2019). Neighbourhood effects and beyond: Explaining the paradoxes of inequality in the changing American metropolis. Urban Studies, 56(1), 3-32.

Smarts, 2012. (2012). Well-being in London: Measurement and use. GLA Economics Current Issues Note 35, Greater London Authority, London

Sørensen, J. F. L. (2014). Rural-Urban differences in life satisfaction: Evidence from the European Union. Regional Studies, 48(9), 1451-1466.

Sørensen, J. F. L. (2021). The rural happiness paradox in developed countries. Social Science Research. https://doi.org/10.1016/j.ssresearch.2021.102581

Statistics Finland. (2021). Paavo postal code area statistics. Online source https://www.stat.fi/tup/paavo/ index_en.html (Accessed 18.3.2021)

Subramanian, S. V., Kawachi, I., \& Kennedy, B. P. (2001). Does the state you live in make a difference? Multilevel analysis of self-rated health in the US. Social Science \& Medicine, 53(1), 9-19.

SYKE Finnish Environment Institute. (2021). Urban rural classification. Online source: https://www. ymparisto.fi/enUS/Living_environment_and_planning/Community_structure/Information_about_the_ community_structure/Urbanrural_classification (Accessed 18.3.2021)

Wang, D., Schwanen, T., \& Mao, Z. (2019). Does exposure to richer and poorer neighborhoods influence wellbeing? Cities, 95, 102408.

Weckroth, M., \& Kemppainen, T. (2021). (Un)Happiness, where are you? Evaluating the relationship between urbanity, life satisfaction and economic development in a regional context. Regional Studies, Regional Science, 8(1), 207-227.

Wirth, L. (1938). Urbanism as a way of life. The American Journal of Sociology, 44(1), 1-24.

Publisher's Note Springer Nature remains neutral with regard to jurisdictional claims in published maps and institutional affiliations. 


\section{Authors and Affiliations}

\section{Mikko Weckroth $^{1,2}$ (D) Sanna Ala-Mantila ${ }^{2} \cdot$ Dimitris Ballas $^{3} \cdot$ Thanasis Ziogas $^{3}$. Jonna Ikonen ${ }^{4}$}

Sanna Ala-Mantila

sanna.ala-mantila@helsinki.fi

Dimitris Ballas

d.ballas@rug.nl

Thanasis Ziogas

a.ziogas@rug.nl

Jonna Ikonen

jonna.ikonen@thl.fi

1 Natural Resources Institute Finland (LUKE), Rural Studies, Land Use and Natural Resource Governance, Yliopistokatu 6, 80100 Joensuu, Finland

2 Helsinki Institute of Sustainability Science (HELSUS), University of Helsinki, PL 4 (Yliopistonkatu 3), 00014 Helsinki, Finland

3 Faculty of Spatial Sciences, University of Groningen, Groningen, The Netherlands

4 Finnish Institute for Health and Welfare (THL), Helsinki, Finland 